\title{
A ESSÊNCIA dO HEBRAICO
}

\author{
Ana Szpiczkowski*
}

\begin{abstract}
Resumo: A palavra hebraica é gerada, de uma raiz, composta, geralmente, por três letras consonantais. Essas três letras consistem na essência da palavra e irão permitir, por sua derivação, a formação de outras. É possível, portanto, à partir de sua raíz, analisá-la semânticamente e obter a revelação de seu verdadeiro sentido. Entretanto, em alguns casos, o radical diz respeito à mais de um campo semântico, pelo fato de serem de origens diferentes, pois no hebraico moderno coexistem, indistintamente, elementos lingüísticos de todas as fases anteriores de sua utilização (período biblico, periodo talmúdico e literatura da Idade Média).

Como exemplo, para esse estudo, foram escolhidas as palavras אמן Amen e Eden - עוע, que transmitem algo, não somente para os hebraistas, mas que, por sua abrangêcia, fazem parte do saber universal.
\end{abstract}

Palavras-chave: radical, três letras consonantais, coexistência de elementos lingüisticos, análise semântica e lingüistica.

Quando nos deparamos com uma língua, qualquer que seja, e enveredamos na compreensão de seus vocábulos, iremos nos encontrar, inevitavelmente, com a história e os valores do povo que a usa.

Isso ocorre, também, com a língua hebraica, a qual, permite, pelo entendimento de suas palavras e pelo rastreamento da sua composição, a compreensão do processo de pensamento e da cultura do povo judeu.

O hebraico, língua clássica, após muitos séculos de utilização para as práticas religiosas, para a comunicação escrita e para a expressão literária, transformou-se, à partir do empenho de Eliezer Ben Yehuda, numa língua moderna, capaz de expressar as necessidades de uma sociedade moderna e dinâmica.

Atualmente, após cento e sete anos do início do renascimento do hebraico, a maioria das inovações para a criação de novos termos continua sendo feita, pela Academia de Língua Hebraica, a partir da adequação dos

* A autora é Prof ${ }^{\mathrm{a}}$. Dr ${ }^{\mathrm{a}}$. do Departamento de Línguas Orientais da FFLCH/USP. 
radicais das fontes tradicionais, acrescidos de prefixos e sufixos, ou ainda, combinando várias palavras básicas para criar uma nova.

A ordem de prioridade das fontes pesquisadas por esta Academia para a formação de novos vocábulos foi, em primeiro lugar a Bíblia, depois o Talmude, e em seguida a vasta literatura da Idade Média, demonstrando, por esse método de trabalho, uma preocupação constante de que o acréscimo de novos vocábulos, não afete as características básicas da língua.

No hebraico moderno, portanto, coexistem, indistintamente, elementos lingüísticos de todas as fases anteriores de sua utilização.

Na língua hebraica há vinte e duas (22) consoantes, que são escritas da direita para a esquerda e, dez (10) vogais, que são sinais diacríticos escritos sob, sobre e ao lado das consoantes (nem sempre presentes na escrita sem vogais).

A palavra hebraica é gerada, de uma raíz, composta, geralmente, por tres letras consonantais. Essas tres letras consistem na essência da palavra e irão permitir, por sua derivação, a formação de outras.

Isso significa que, ao nos determos em uma palavra hebraica, poderemos, à partir de sua raíz, analisá-la semânticamente e obter a revelação de seu verdadeiro sentido. Entretanto, em alguns casos, o radical diz respeito a mais de um campo semântico, pelo fato de eles serem de origens diferentes.

Tomemos como exemplo a pequena palavra hebraica Amen - ממא, presente e popular em tantas outras línguas, e que revela ao mundo uma das essências da civilização judaica, a afirmação. Sua popularidade se dá, talvez, porque ela é a resposta afirmativa que se dá após uma bênção ou uma oração.

A raiz Aman - ומא, quando utilizada para o verbo, significa "criar, educar; amarrar, juntar". Sua equivalência mais próxima em outras línguas, pode ser encontrada no inglês americano moderno, na expressão Right On.

$\mathrm{Na}$ medida em que essa palavra viajou através do tempo, na história judaica, ela foi sofrendo transformações, de caráter morfológico e semântico.

Festa judaica. Comemora, em quatorze de Adar, a história do Livro de Ester, que é lida de um rolo manuscrito (Meguilá). Origina-se do persa, e significa "lançar a sorte". 
A história de Purim $^{1}$, por exemplo, relatada no livro de Ester, registra um desses primeiros significados, quando utiliza a raiz Aman - מא ), para relatar que Mardoqueu foi o Omen - און de Hadassa, isto é, a pessoa que a criou, seu tutor.

A palavra Omanut - נמאתו (a terceira letra da raíz, o "j", quando inserida no meio da palavra recebe a forma de "J"), cuja tradução é arte, origina-se, como podemos observar por sua composição, da mesma raíz. Isso, porque, a obra artística, além da habilidade, exige, também, treino e exercício - Imun - אימון, em hebraico.

Àqueles que acreditam que a medicina é uma arte, a expressão Rofe Oman - médico especialista, criada pela combinação de dois vocábulos básicos, demonstra o estabelecimento de relações morfológicas e semânticas para a sua criação, além de outras associações possíveis, tais quais as de caráter filosófico.

A palavra Amana - נמאה ( o "ן" recebe a forma de "J"), significa convênio, aliança, crença e, também, crédito monetário.

A Convenção de Genebra, por exemplo, recebe em hebraico a nomenclatura Omnat Geneva - de נמאג ת'הבנ, enquanto Isch Amana שיא נמאה , significa "fiel" (composição das palavra:homem e crença) e, KtanAmana - וטק-נמאה, (composição das palavras: pequeno e crença) quer dizer "cético, sem crença".

A pergunta Ha-umnam - הנמאם, cujo significado é: "será que?", “é possível?" pode nos ajudar a explorar um outro filão de seu significado. Esse mesmo vocábulo, na forma afirmativa Omnam - נמאם, significa "certamente", "deveras", "na verdade". A palavra "verdade" - Emet מאת, provém da palavra Emenet - נמאת, baseada na mesma fonte, e que, com o passar do tempo, perdeu a letra "J". Os traços da letra "J" podem ser encontrados na palavra Neeman - נוא " "נמא, que significa "ser fiel","ser de confiança".

Outro exemplo interessante da derivação de radicais no hebraico pode ser dado pelas três letras que compõem a palavra $\boldsymbol{E d e n}-\boldsymbol{y} \boldsymbol{y}$ ). Nesse caso, todos os seus derivados pertencem ao mesmo campo semântico. 
Há no hebraico uma série de sinônimos para o conceito de prazer, mas um dos mais fascinantes é encontrado na Bíblia, pela forma com que a matriarca Sara reage à notícia de que ela se tornará mãe, quando ela pergunta:" Terei ainda deleite depois de haver envelhecido..." (Gênesis, 18:12). A palavra "deleite" no texto original hebraico aparece como נדעה, da mesma raíz.

No próprio livro de Gênesis (2:8), encontramos referência à criação

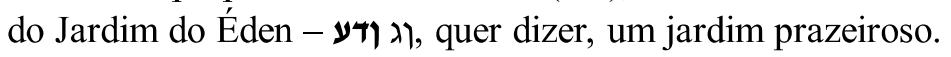

No Talmude, Gan Eden - וג ודע é o nome que se dá ao prometido mundo vindouro.

No hebraico moderno, o termo Oden - עדן, significa "prazer, deleite, delicadeza". Quando as pessoas querem se referir de maneira entusiástica à וג ודע תומדא ילע - respeito de um lugar, dizem: Gan Eden Alei Adamot (o paraíso na terra).

A expressão Taam Gan Eden - וג סעט ודע (gosto do Éden-literal) é utilizada para se referir a algo delicioso. À propósito, a marca registrada de uma água mineral em Israel é Mei Eden - מדו ודע (as águas do Éden).

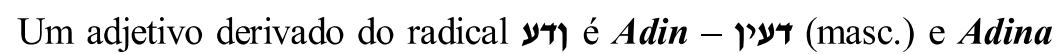
(fem.) - דעינה, cujo significado é "delicado (a)", "refinado (a)".

A palavra Maadan - מןדע, além de prazer e deleite, significa, também, dentre outras explicações, "guloseima, iguaria". Assim, a palavra Maadanya - מנדעהי, oriunda do mesmo radical, pois como já afirmamos acima, o "l", quando no meio da palavra, passa a ser "J", significa "casa de iguarias", "casa de delicatessen".

A forma verbal da raiz ודע é utilizada para "mimar, refinar, enobrecer, tornar delicado ".

" As expressões Hayei Maadanim - (vida de prazeres), do hebraico moderno, assim como Idnu Maadanay - נדען מנדעי (deleitem-se com minhas iguarias), do hebraico medieval, vêm confirmar aquilo que afirmamos no início desse estudo:a preocupação lingüística dos hebraístas em preservar as raízes da língua hebraica.

Tal preocupação, no entanto, não impede que o hebraico mantenha suas características de língua moderna, em constante atualização. Os 
estrangeirismos, presentes, praticamente, em todas as línguas modernas, exigem, daqueles que possuem o interesse em preservar a pureza lingüística, muita atenção para a criação de vocábulos hebraicos. Mas o hebraico, como todas as línguas, dispõe até mesmo de gíria própria, utilizando dentre outros, elementos do ídiche e do árabe.

A escolha dos radicais ומדע e, para esse estudo, não se deu ao acaso. Vários outros poderiam ter sido selecionados para mostrar a linha de raciocínio que comanda a formação dos vocábulos hebraicos. Houve aqui, entretanto, uma preocupação em buscar no vasto repertório que compõe a língua hebraica, aqueles radicais que transmitam algo, não somente para os hebraístas, mas que sejam mais abrangentes, e façam parte do saber universal.

Para finalizar, concluímos que o estudo dos radicais hebraicos vai além de sua simples análise lingüística. Inclui a possibilidade de conhecimento da realidade de vida do falante do hebraico, da maneira como ele sente e pensa.

A língua hebraica, com seus nomes e verbos, adjetivos e advérbios, ativos e passivos, em que todos são remetidos à raíz de três letras consonantais, convidam e encorajam o estudioso para uma viagem pela história e pela cultura do povo judeu, o núcleo de sua essência.

\section{BibLIOGRAFIA}

"A Bíblia Sagrada", Rio de Janeiro, Sociedade Bíblica do Brasil, tradução de João Ferreira de Almeida,1957.

“A Lei de Moisés - e as "Haftarot” - Rio de Janeiro, S. Cohen \& Cia. Ltda., 1968, tradução, explicações e comentários do Rabino Meir Masliah Melamed.

BEREZIN, Rifka "Dicionário Hebraico-Português”, EDUSP, São Paulo, 1995.

LOWIN, Joseph "Hebrewspeak, An Insider's Guide to the Way Jews Think", Jason Aronson Inc., Northvale, New Jersey, London, 1995.

UNTERMAN, Alan "Dicionário Judaico de Lendas e Tradições", Jorge Zahar Editor, Rio de Janeiro, 1994, tradução de Paulo Geiger. 
Abstract: The Hebrew word derives from a root. Usually it is composed of three consonantal letters. These make up a word which will generate other words. Thus, it is possible to analyze semantically the word, and get its real meaning from its root.

However, in some cases, the radical is subject to more than one semantic field, given that they are from different origins.

In modern Hebrew, regardless of linguistic elements which are from phases prior to its use (biblical period, talmudic period, and Middle Ages literature) they coexit.

For example to this study, we have chosen the words Amen and Eden which translate not Therefore, they are part of the universal knowledge.

Keywords: radical, three consonantal letters coexistence linguistic elements, semantic and linguistic analysis. 